\title{
Strategies to prevent neuronal damage in pediatric bacterial meningitis
}

\author{
Denis Grandgirard and Stephen L. Leib
}

\section{Purpose of review}

The mortality of bacterial meningitis can reach 30\%, and up to $50 \%$ of survivors suffer from persisting neurological deficits as a consequence of the disease. The incidence of neurological sequelae of bacterial meningitis has not improved over the last decade. Adjunctive therapeutic options are limited, and ongoing research into the pathophysiology of brain damage in bacterial meningitis aims at providing the scientific basis for future development of more efficient adjunctive options.

\section{Recent findings}

In a population with good access to health care, dexamethasone given before or at the time of initiation of antibiotic therapy acts beneficially in pediatric pneumococcal meningitis, but not in meningococcal meningitis. In experimental animal models, brain-derived neurotrophic factor protected against brain injury and improved hearing while melatonin, which has antioxidant properties among other effects, reduced neuronal death. Transgene technology can be used to provide new insights into the pathophysiology of the disease and to identify potential therapeutic targets.

\section{Summary}

Although dexamethasone improves outcome of bacterial meningitis under defined circumstances, the morbidity of bacterial meningitis still remains unacceptably high.

Experimental models may help to identify new therapeutic strategies to further improve the neurological outcome in young children suffering from bacterial meningitis.

\section{Keywords}

adjunctive therapy, bacterial meningitis in children, neuronal damage

Curr Opin Pediatr 18:112-118. (C) 2006 Lippincott Williams \& Wilkins.

Institute for Infectious Diseases, University of Bern, Switzerland

Correspondence to Professor Stephen L. Leib, University of Bern, Institute for Infectious Diseases, Friedbuehlstrasse 51, Bern, 3010, Switzerland

Tel: +41 31632 4949, fax: +41 31632 3550; e-mail: Stephen.leib@ifik.unibe.ch

Current Opinion in Pediatrics 2006, 18:112-118

\section{Abbreviations}

BDNF brain-derived neurotrophic factor

CSF cerebrospinal fluid

GBS Group B streptococcus

MMP matrix-metalloproteinases

TACE TNF- $\alpha$ converting enzyme

TLR Toll-like receptor

WBC white blood cell

\section{Introduction}

Bacterial meningitis, and in particular meningitis of children, is associated with devastating mortality rates of up to $30 \%$. Moreover, $20-50 \%$ of pediatric patients who survive the infection have serious and permanent neurological sequelae, which include deafness, mental retardation and learning impairment, sensory-motor deficits, seizure disorders and cerebral palsy. The incidence of neurologic sequelae of bacterial meningitis in children has not significantly improved over the last decade [1]. For example, comparison of two timely distinct national prospective studies performed in England and Wales showed a decrease in the acute phase mortality from $22 \%$ in the time period from 1985 to 1987 to $6.6 \%$ in the time period from 1996 to 1997. In contrast, the corresponding follow-up studies on the incidence of serious disabilities in the surviving patients showed an incidence of $25.5 \%$ in the time period from 1985 to 1987 and an incidence of $23.5 \%$ in the time period from 1996 to 1997. Compared with general practice or hospital control patients, children that survived bacterial meningitis had a fourfold to 16 -fold increase in the risk of developing severe disabilities [ $2^{\circ}$ ]. Even 12 years after the disease, survivors of meningitis are at greater risk of deficits in intellectual, academic and executive ability than grade-matched and gender-matched controls. As a consequence, children after meningitis are more than twice as likely as controls to require special educational assistance (27.0\% compared with $12.5 \%$ ). A younger age at illness is associated with a poorer efficiency in performing linguistic and executive functions, and may suggest that cerebral insult may have a greater impact on a developing brain $\left[3^{\circ}\right]$. Group B streptococcus (GBS) is the most common etiological agent in neonates and Streptococcus pneumoniae and Neisseria meningitidis are the most common causes of bacterial meningitis in infants and young children worldwide $\left[4^{\bullet \bullet}\right]$. Pneumococcal meningitis is consistently associated with a particularly high incidence of neurological sequelae, with up to half of the survivors presenting some form of neurological deficits [5,6]. A retrospective study of 49 patients admitted in a single pediatric intensive care unit between 1990 and 2002 in France and diagnosed with pneumococcal meningitis recorded a mortality rate of $49 \%$ and neurological impairment in $48 \%$ of patients discharged from the hospital with a mean follow-up of 5 years (range $1-12$ years) $\left[7^{\circ}\right]$. 
Brain injury caused by bacterial meningitis prominently affects three brain structures, namely the cortex, the hippocampus and the inner ear. As shown in pathologic studies in patients dying from bacterial meningitis and in corresponding animal models, the cortical regions of the brain display areas of acute neuronal injury associated with areas of focal ischemic necrosis [8]. In the hippocampus, apoptotic damage occurs in the inner blade of the dentate gyrus and this damage has been associated with impairment of learning and memory in experimental models of pneumococcal meningitis $[9,10]$. The vulnerable cells in the dentate gyrus have been identified to include immature neurons recently generated from stem cells [11]. Necrotic cell death is also observed in the CA1-CA4 sectors of the hippocampus, and in the dentate gyrus, particularly in adult mice, when the damage is severe [12]. A different form of hippocampal damage characterized by clusters of shrunken and pyknotic nuclei affects cells spanning the entire blade of the dentate gyrus in newborn rats infected with GBS [11].

Hearing impairment is the most common neurological sequel following meningitis and is observed in up to $30 \%$ of patients, depending on the infecting pathogen [13-15]. In an adult rat model of pneumococcal meningitis the severity of permanent hearing impairment assessed two weeks after the infection correlated significantly with the loss of type I spiral ganglion neurons [16]. Thus neuronal loss in the spinal ganglion represents a histomorphological correlate of hearing impairment.

In the time period covered in this review (11/2004 to 9/2005), a number of pathogenetic factors have been evaluated for their contribution to the development of brain damage in bacterial meningitis. Matrix-metalloproteinases (MMP) have been shown to facilitate the extravasation of white blood cells (WBCs) and to participate in blood-brain barrier disruption by degrading components of the basal lamina of the cerebral vasculature $\left[17^{\circ}\right]$. The presence of reactive oxygen species and reactive nitrogen species leads to the production of peroxinitrite and the occurrence of lipid peroxidation, as observed in inflammatory cells and penetrating cortical blood vessels in brain specimens from patients [18]. In addition, oxidants have been shown to induce DNA strand breakage and subsequent poly(ADP ribose) polymerase activation, initiating an energy-consuming intracellular cycle that ultimately leads to cellular energy depletion and death, specifically in endothelial cells of the cerebral vasculature [19]. Finally, sustained cytokine production, especially IL-1 $\beta$, has been shown to correlate with adverse disease outcome and/or severity of disease [20].
Factors found to contribute to ischemic injury include the production of vasoconstrictive endothelins, the activation of platelets and the induction of a procoagulant state [21].

Different bacterial toxins have been shown to directly trigger the host apoptotic machinery: S. pneumoniaeproduced pneumolysin and hydrogen peroxide have been shown to exert neurotoxicity in vitro and in an experimental model of pneumococcal meningitis [22]. Hemolysin may play a role during GBS meningitis, since it has been shown to induce apoptosis [23].

\section{Strategies for preventing neuronal damage during bacterial meningitis: current concepts}

In the time period covered by this review (11/2004 to 9/2005) the pathogenetic mechanisms identified as targets for adjuvant therapy include the following:

(1) bacterial killing and the prevention of associated release of bacterial components $\left[24^{\bullet \bullet}, 25,26^{\bullet}, 27^{\bullet}\right]$;

(2) the host mechanisms for recognition of bacteria or bacterial components and the initiation of the inflammatory reaction $\left[28^{\bullet}, 29^{\bullet}, 30,31^{\circ}, 32^{\bullet}, 33^{\bullet}, 34^{\bullet}, 35\right]$;

(3) the modulation of the inflammatory reaction by adjuvant therapy with dexamethasone $\left[4^{\bullet \bullet}, 7^{\bullet}, 36^{\bullet \bullet}\right.$, $\left.37,38^{\bullet}, 39^{\bullet}, 40^{\bullet}\right]$;

(4) the inhibition of inflammatory and/or neurotoxic mediators $\left[41,42^{\bullet}, 43^{\bullet}, 44,45^{\circ}, 46^{\circ}\right.$ ];

(5) the modulation of apoptotic pathways $\left[47,48^{\circ}, 49^{\circ}\right.$, $\left.50^{\circ}\right]$.

\section{Bacterial killing and the prevention of associated release of bacterial components}

Bacteria and their components engage the innate immune response through activation of the members of Toll-like receptors (TLRs), including TLR2 and TLR4. Antibiotic therapy reduces the overall release of these components, when compared to unhindered replication and subsequent autolysis. Bacteriolytic antibiotics, however, have been shown to induce an initial brisk release of bacterial components that may accentuate inflammation. The use of antibiotics that inhibit $\mathrm{RNA} /$ protein synthesis or DNA replication (rifamycins, macrolides, clindamycin, ketolides and quinolones) reduces bacterial lysis [ $24^{\bullet \bullet}$ ]. For example, the production of inflammatory mediators by murine macrophages is decreased when stimulated by GBS exposed to rifampin or clindamycin compared with ampicillin or cefotaxime [25]. Rifampicin, given 6 hours prior to ceftriaxone, reduced the release of bacterial components into the cerebrospinal fluid (CSF) and attenuated neuronal injury in the hippocampus [51]. Similarly, clindamycin lowered extracellular concentration of hydroxyl radicals 
and glutamate, and decreased neuronal apoptosis in the dentate gyrus in a rabbit model of pneumococcal meningitis $\left[26^{\circ}\right]$. The cyclic lipopeptide daptomycin kills bacteria by inducing a rapid depolarization of the bacterial membrane without subsequent disruption and has been suggested as a candidate for the treatment of gram-positive bacterial meningitis $\left[27^{\circ}\right]$.

\section{Recognition of bacterial components and the initiation of the inflammatory reaction}

The brain's inflammatory response to bacterial infection determines the outcome of bacterial meningitis, that is, the extent of brain injury as a consequence of the disease. Thus, adjuvant therapeutic strategies include targeting the inflammatory reaction as early and as upstream as possible. Early events in the inflammatory cascade are the recognition of the pathogens, the resulting immune activation, the recruitment of WBCs in the $\mathrm{CSF}$ and the release of inflammatory mediators into the subarachnoid space. Therapeutic strategies developed with this aim strive to leave the beneficial components of inflammation in place, but to attenuate the harmful ones (reviewed in [23]).

Recent data generated in experimental models concern the recognition of the pathogen and the initiation of the immune reaction. CD14 myeloid receptor, TLRs and MyD88 have all been implicated in immune activation. CD14 ${ }^{-/-}$mice showed a higher mortality from infection by $S$. pneumoniae whereas the systemic host defence and the CSF bacterial clearance were not affected. The authors suggested, however, that CD14 deficiency leads to a stronger neutrophil recruitment into the CSF and an excessive meningeal inflammation $\left[2^{\circ}\right]$.

TLR2 is involved in the recognition of gram-positive pathogens. TLR2 deficiency leads to an increased severity of the disease and earlier mortality in murine models of pneumococcal meningitis. A stronger accumulation of bacteria in the ventricules and the meninges has also been observed. A delay in granulocyte recruitment and a weakened antimicrobial capacity are believed to contribute to the failing host response in TLR2 deficient mice [52]. TLR2 has also been recently suggested to play a role in the regulation of TNF-alpha gene expression in the brain during pneumococcal meningitis; TLR2 deficiency is associated with enhanced TNF gene expression in the brain [30].

MyD88, which acts downstream of TLR2, is necessary to mount a robust immune response to $S$. pneumoniae in the central nervous system. In transgenic animals lacking MyD88, a marked reduction of CSF pleocytosis and a decreased expression of cytokines and chemokines were observed. MyD88 deficiency, however, was associated with a worsening of the clinical disease, owing to a more severe bacteremia and an enhanced expression of TNF-alpha in the lungs [34 $4^{\circ}$.

The hypothesis that avoiding leukocyte recruitment in the CSF in order to decrease the local inflammatory reaction, which would then be beneficial, has recently been challenged by Brandt et al. [31 $1^{\circ}$. For example, treatment with Fucoidin initiated at the time of infection in experimental pneumococcal meningitis led to a higher mortality, but had no measurable effect on brain damage or bacterial numbers in the CSF compartment. The highest mortality was associated with an increase in the numbers of bacteria in the blood, suggesting that leukocyte blockade affected the host's ability to control systemic but not central nervous system infection. This hypothesis was supported by the observation that the boosting of the peripheral neutrophil count by pretreatment with granulocyte-colony-stimulating factor (G-CSF) reduced mortality and prevented brain damage, and led to reduced numbers of bacteria in the blood and the CSF [ $\left.33^{\circ}\right]$. Thus, the degree of systemic infection and the severity of brain damage are likely to contribute independently to mortality. This hypothesis may be supported by the apparent discrepancies between the previously mentioned study of Brandt and a recent study that reported the reduction of leukocyte influx by treatment with a tyrosine kinase inhibitor (tyrphostin AG126). This study [32 ${ }^{\circ}$ in pneumococcal-cellwall-induced meningitis showed that the attenuation of CSF-pleocytosis reduced the increases in blood flow and intracranial pressure.

Fas (CD95) and Fas ligand (FasL, CD95L) have been shown to be involved in the acute inflammatory response by attracting neutrophils and regulating their survival [53,54]. Increased levels of soluble Fas and FasL have been found in CSF of patients with bacterial meningitis. Recent data generated in experimental models using transgenic animals that lack Fas and FasL, however, could not find a contribution of Fas/FasL in the regulation of inflammatory response during pneumococcal meningitis [35].

From the data generated in the reviewed period one might conclude that a higher neutrophil count before the initiation of antibiotic therapy is beneficial to limit the spread of infection and the development of severe bacteremia. Once antibiotic therapy has been initiated, however, the contribution of neutrophils to bacterial clearance in the CSF seems small and pales in comparison to the detrimental effect of high CSF pleocytosis on brain tissue. 


\section{Modulation of the inflammatory reaction by adjuvant therapy with dexamethasone}

Given the contribution of excessive inflammation to the development of brain damage in bacterial meningitis, anti-inflammatory adjuvant treatment with dexamethasone has been tested in several controlled clinical trials. Addressing a complete and critical overview on this topic goes beyond the scope of this review, but has been recently done by others $\left[36^{\bullet \bullet}, 55^{\bullet \bullet}, 56^{\bullet \bullet}\right]$. For meningococcal meningitis, dexamethasone was not proven to be effective in decreasing sequelae among pediatric patients in a recent study performed in Brazil [ $40^{\circ}$ ]. Another recent retrospective population-based study performed in Sydney (1994-1999) in childhood pneumococcal meningitis demonstrated that, in a population with good access to health care, early recognition of pneumococcal meningitis and treatment with adjunctive dexamethasone significantly improved mortality and severe disabilities in survivors [39 ${ }^{\circ}$. In another study performed in a pediatric intensive care unit in France $\left[7^{\bullet}\right]$, dexamethasone treatment did not influence in-hospital death in a multivariate analysis; however, the beneficial effect may have been reduced by the delay between antibiotic and steroid administration and the selection of a high-severity population (49\% mortality).

Experimental studies on the use of adjunctive dexamethasone have generated conflicting data. Whereas dexamethasone treatment was shown to increase both acute hippocampal injury and long-term learning deficits in an infant rat model [57], it decreased neurological sequelae and caspase activity in an adult rat model [37]. The measured outcomes, however, were different in these two studies (hippocampal injury in the first, caspase activity in the cerebellum in the second study), as well as the protocol for assessment of learning capacity; a direct comparison is therefore not possible.

\section{Inhibition of inflammatory and/or neurotoxic mediators}

Gene knockout technology combined with experimental meningitis in mice has been used to investigate the role of inflammation in the development of brain injury. This has been recently reviewed by Paul et al. [46 ${ }^{\bullet \bullet}$. In TNF- $\alpha$ knockout mice, mortality and spatial memory deficits were increased in ceftriaxone-treated experimental pneumococcal meningitis [41]. TNF- $\alpha$ has been shown, however, to participate in postmeningitic hearing loss, which was reduced by blockade with neutralizing antibodies in a Mongolian gerbil model [44]. Few other selective intervention strategies have been directed against specific cytokines so far, and ongoing research focuses on the pattern and kinetic of cytokine expression during bacterial meningitis [45 $\left.{ }^{\circ}\right]$. Thus a deeper understanding of the role of the various media- tors in the inflammatory network is a prerequisite for the development of individual targets for adjuvant therapy.

A number of strategies have been evaluated in infant models of bacterial meningitis, which, until now, have not been translated into clinical use (see Table 1). One main challenge seems to be the difficulty in finding therapies that are able to attenuate both hippocampal and cortical damage in bacterial meningitis. For example, experimental therapies using metalloproteinase inhibitors are generally protective against cortical damage. Furthermore, MMP-inhibition combined with inhibition of TNF- $\alpha$ converting enzyme (TACE) inhibitory activity has been shown in one study to also protect from hippocampal dentate gyrus injury. The beneficial effect on both forms of injury by an MMP/TACE inhibitor, however, was restricted to one compound and could not be shown for other similar MMP/TACE inhibitors. Thus the beneficial effect of MMP/TACE inhibition may not directly depend on the TACE inhibitory activity $\left[42^{\bullet}, 58,59\right]$. Antioxidant therapy has been shown to protect the neocortex from damage, but not from hippocampal apoptosis. The beneficial effect on cortical injury may be attributed to a protective effect on the cerebral microvasculature leading to an amelioration of cerebral perfusion [60]. Recently, the continuous administration of melatonin in a model of ceftriaxone-treated pneumococcal meningitis in rabbit has been shown to decrease hippocampal apoptosis. Whether the observed effect was due to the radical scavenging properties of melatonin or to its influence on neurotrophic factors' expression remains to be clarified $\left[43^{\circ}\right]$.

\section{Modulation of apoptotic pathways}

Caspase inhibitors have been previously shown to attenuate hippocampal apoptosis in the dentate gyrus. While the beneficial effect of the pan-caspase inhibitor $\mathrm{z}$ VAD-fmk could be attributed to the down-modulation of the inflammatory response and associated reduction of caspase inhibition [61], the specific inhibition of caspase-3 with Ac-DEVD-CHO relied solely on the interference with the apoptotic pathway [62]. Recently, it has been suggested that two phases of apoptosis were discernible. Neuronal injury at $18 \mathrm{~h}$ after infection was independent of the caspase-3 pathway, and neuronal cell death at $24 \mathrm{~h}$ after infection was attenuated in the absence of the caspase-3 pathway [47]. Pharmacological interventions aimed at increasing the survival rate of neurons in pediatric patients with meningitis will therefore need to take the kinetic aspects of the development of brain damage into account. Administration of exogenous brain-derived neurotrophic factor (BDNF) has been shown to attenuate all forms of brain damage associated with pneumococcal and GBS meningitis [48 ${ }^{\circ}$. The therapeutic strategy of exogenous BDNF administration has 
Table 1 Therapeutic interventions in the infant rat models and their effect on cortical and hippocampal injury, as well as survival (partially adapted from $[21,64]$ ). Only new findings covering the period of the review are referenced

\begin{tabular}{|c|c|c|c|c|c|c|}
\hline \multirow[b]{2}{*}{ Intervention } & \multirow[b]{2}{*}{ Compound } & \multirow[b]{2}{*}{ Pathogen } & \multicolumn{2}{|c|}{ Neuronal injury } & \multirow[b]{2}{*}{ Mortality } & \multirow{2}{*}{$\begin{array}{l}\text { Recent } \\
\text { references }\end{array}$} \\
\hline & & & Cortex & Hippocampus & & \\
\hline iNOS inhibition & Aminoguanidine & GBS & increase & ND & ND & \\
\hline Endothelin agonist & Bosentan & SP & decrease & no change & no change & \\
\hline Antioxidants & PBN & $\begin{array}{l}\text { SP } \\
\text { GBS }\end{array}$ & $\begin{array}{l}\text { decrease } \\
\text { decrease }\end{array}$ & $\begin{array}{l}\text { increase } \\
\text { decrease }^{a}\end{array}$ & $\begin{array}{l}\text { no change } \\
\text { ND }\end{array}$ & \\
\hline & NAC & $\mathrm{SP}$ & decrease & no change & no change & \\
\hline & DFO & SP & decrease & no change & no change & \\
\hline & TLM & SP & decrease & no change & decrease & \\
\hline MMP inhibition & GM-6001 & SP & decrease & ND & ND & \\
\hline MMP + TACE inhibition & BB-1101 & SP & decrease & decrease & decrease & \\
\hline & TNF484 & SP & decrease & non change & no change $\left[42^{\circ}\right]$ & \\
\hline TNF- $\alpha$ neutralization & Neutralizing Ab & GBS & no change & decrease $^{a}$ & decrease ${ }^{b}$ & \\
\hline Attenuation of inflammation & Dexamethasone & $\begin{array}{l}\text { SP } \\
\text { GBS }\end{array}$ & $\begin{array}{l}\text { ND } \\
\text { decrease }\end{array}$ & $\begin{array}{l}\text { increase } \\
\text { ND }\end{array}$ & $\begin{array}{l}\text { no change } \\
\text { no change }\end{array}$ & \\
\hline Caspase inhibition & Ac-DEVD-CHO & SP & ND & decrease & ND & \\
\hline Neurotrophin & BDNF & $\begin{array}{l}\text { SP } \\
\text { GBS }\end{array}$ & $\begin{array}{l}\text { ND } \\
\text { decrease }\end{array}$ & $\begin{array}{l}\text { decrease } \\
\text { decrease }^{a}\end{array}$ & $\begin{array}{l}\text { no change } \\
\text { no change }\end{array}$ & {$\left[48^{*}\right]$} \\
\hline Glutamate antagonist & Kynurenic acid & GBS & decrease & decrease $^{a}$ & ND & \\
\hline
\end{tabular}

iNOS: inducible nitric oxide synthase; PBN: $\alpha$-phenyl-butyl nitrone; NAC: N-acetylcysteine; DFO: deferoxamine; TLM: trylizad-mesylate; SP: Streptococcus pneumoniae; ND: not determined.

${ }^{a}$ Damage in the dentate gyrus of the hippocampus consisting of pyknotic cells, distinct from caspase-dependent apoptosis.

${ }^{b}$ Only when neutralizing antibodies were given systemically, and not intracisternally.

been further supported by the finding that expression of endogenous BDNF was found to be decreased by antibiotic treatment in experimental pneumococcal meningitis [63]. Furthermore, BDNF exerted a protective effect on hearing capacity in experimental pneumococcal meningitis $\left[49^{\circ}\right]$. Thus, BDNF has been shown to modulate caspase-dependent and independent pathways of neuronal damage, but its mechanism of action is still poorly understood.

A new mechanism to trigger apoptosis has recently been proposed $\left[50^{\circ}\right]$. S. pneumoniae was shown to inhibit phosphatidylcholine biosynthesis, presumably by the pneumococcal toxins pneumolysin and/or $\mathrm{H}_{2} \mathrm{O}_{2}$. The inhibition of this pathway causes apoptosis in a variety of brain cells in vitro. In a mouse model of pneumococcal meningitis, hippocampal damage was prevented by treatment with cytidine diphosphocholine.

\section{Summary}

To date, there is no ideal adjunctive therapy for the treatment of bacterial meningitis in all patient populations. The available evidence thus far supports the use of dexamethasone, when given before or together with the first dose of antibiotics, in children and adults with pneumococcal or haemophilus meningitis. Dexamethasone is not recommended for the treatment of meningococcal, gram-negative bacillary meningitis or for bacterial meningitis in neonates $\left[36^{\circ}\right.$ ]. Future research into antibiotic therapy for bacterial meningitis may focus on limiting the release of bacterial components, provided that a sufficiently rapid CSF sterilization can be achieved. Modulation of individual components of the inflammation cascade may be evaluated while cautiously keeping an eye on the systemic effects. This was exemplified by studies on leukocyte recruitment, where a decrease in CSF inflammatory parameters and brain damage did not contribute to a better outcome owing to an increase in severity of the systemic disease. Such 'double-edged swords' are probably hidden in a number of targets currently investigated as adjunctive strategies. The complex network of cytokines, chemokines, their receptors and other inflammatory mediators that participate in CSF inflammation will require more studies before a rational neuroprotection strategy can be developed. Finding a uniform target for adjunctive therapy is further hampered by the different pathophysiologic pathways that lead to the distinct forms of brain damage in bacterial meningitis, that is, necrosis in the cortex, hippocampal apoptosis and damage to the inner ear. Finally, meningitis in neonates, children and adults may need to be considered separately. Future research may therefore include the differences in the pathophysiology of brain damage that arises from meningitis caused by different pathogens and in defined patient populations.

\section{Acknowledgments}

Research grants were provided by the Swiss National Science Foundation (632-66057.01) and the National Institutes of Health (2P50 NS 035902-06). 


\section{References and recommended reading}

Papers of particular interest, published within the annual period of review, have been highlighted as:

- of special interest

$\bullet$ of outstanding interest

Additional references related to this topic can also be found in the Current World Literature section in this issue (pp. 211-212).

1 Harvey D, Holt DE, Bedford H. Bacterial meningitis in the newborn: a prospective study of mortality and morbidity. Semin Perinatol 1999; 23:218225

2 de Louvois J, Halket S, Harvey D. Neonatal meningitis in England and - Wales: sequelae at 5 years of age. Eur J Pediatr 2005; 164:730-734.

Even in countries with good access to health care, no significant improvement was documented regarding prevention of long-term neurological sequelae.

3 Anderson V, Anderson P, Grimwood K, Nolan T. Cognitive and executive

- function 12 years after childhood bacterial meningitis: effect of acute neurologic complications and age of onset. J Pediatr Psychol 2004; 29:67-81.

The age at the onset of disease contributes to long-term intellectual, academic and executive deficits.

4 Yogev R, Guzman-Cottrill J. Bacterial meningitis in children: critical review of -• current concepts. Drugs 2005; 65:1097-1112.

An overview on actual recommendations for the treatment of bacterial meningitis in children.

5 De Beek Dv D, Schmand B, De Gans J, et al. Cognitive impairment in adults with good recovery after bacterial meningitis. J Infect Dis 2002; 186:10471052 .

6 Merkelbach S, Sittinger H, Schweizer I, Muller M. Cognitive outcome after bacterial meningitis. Acta Neurol Scand 2000; 102:118-123.

7 Wasier AP, Chevret L, Essouri S, et al. Pneumococcal meningitis in a pedia-

- tric intensive care unit: prognostic factors in a series of 49 children. Pediatr Crit Care Med 2005; 6:568-572.

The use of dexamethasone had no effect on mortality in pediatric patients on an intensive care unit.

8 Scheld WM, Koedel U, Nathan B, Pfister HW. Pathophysiology of bacterial meningitis: mechanism(s) of neuronal injury. J Infect Dis 2002; 186:S225S233.

9 Loeffler JM, Ringer R, Hablutzel M, et al. The free radical scavenger alphaphenyl-tert-butyl nitrone aggravates hippocampal apoptosis and learning def icits in experimental pneumococcal meningitis. J Infect Dis 2001; 183:247252

10 Wellmer A, Noeske C, Gerber J, et al. Spatial memory and learning deficits after experimental pneumococcal meningitis in mice. Neurosci Lett 2000; 296:137-140.

11 Bifrare YD, Gianinazzi C, Imboden H, et al. Bacterial meningitis causes two distinct forms of cellular damage in the hippocampal dentate gyrus in infant rats. Hippocampus 2003; 13:481-488

12 Gerber J, Raivich G, Wellmer A, et al. A mouse model of Streptococcus pneumoniae meningitis mimicking several features of human disease. Acta Neuropathol (Berl) 2001; 101:499-508.

13 Kesser BW, Hashisaki GT, Spindel JH, et al. Time course of hearing loss in an animal model of pneumococcal meningitis. Otolaryngol Head Neck Surg 1999; 120:628-637.

14 Woolley AL, Kirk KA, Neumann AM Jr. et al. Risk factors for hearing loss from meningitis in children: the Children's Hospital experience. Arch Otolaryngol Head Neck Surg 1999; 125:509-514.

15 Oostenbrink R, Maas M, Moons KG, Moll HA. Sequelae after bacterial meningitis in childhood. Scand J Infect Dis 2002; 34:379-382.

16 Klein M, Koedel U, Pfister H-W, Kastenbauer S. Morphological correlates of acute and permanent hearing loss during experimental pneumococcal meningitis. Brain Pathol 2003; 13:123-132.

17 Sellner J, Leib SL. In bacterial meningitis cortical brain damage is associated

- with changes in parenchymal MMP-9/TIMP-1 ratio and increased collagen type IV degradation. Neurobiol Dis 2005; Oct 26. [Epub ahead of print].

Endogenous mechanisms of metalloproteinase regulation in bacterial meningitis.

18 Kastenbauer S, Koedel U, Becker BF, Pfister HW. Oxidative stress in bacterial meningitis in humans. Neurology 2002; 58:186-191.

19 Koedel U, Winkler F, Angele B, et al. Meningitis-associated central nervous system complications are mediated by the activation of poly(ADP-ribose) polymerase. J Cereb Blood Flow Metab 2002; 22:39-49.

20 Täuber MG, Moser B. Cytokines and chemokines in meningeal inflammation: biology and clinical implications. Clin Infect Dis 1999; 28:1-11.
21 Koedel U, Scheld WM, Pfister HW. Pathogenesis and pathophysiology of pneumococcal meningitis. Lancet Infect Dis 2002; 2:721-736.

22 Braun JS, Sublett JE, Freyer D, et al. Pneumococcal pneumolysin and H(2)O (2) mediate brain cell apoptosis during meningitis. J Clin Invest 2002; 109: $19-27$.

23 Van der Flier M, Geelen SP, Kimpen JL, et al. Reprogramming the host response in bacterial meningitis: how best to improve outcome? Clin Microbiol Rev 2003; 16:415-429.

24 Nau R, Eiffert H. Minimizing the release of proinflammatory and toxic bacter-

-. ial products within the host: a promising approach to improve outcome in life-threatening infections. FEMS Immunol Med Microbiol 2005; 44:1-16.

How antibiotic therapy may be adapted in order to minimize the inflammatory reaction.

25 Brinkmann KC, Talati AJ, Akbari RE, et al. Group B streptococci exposed to rifampin or clindamycin (versus ampicillin or cefotaxime) stimulate reduced production of inflammatory mediators by murine macrophages. Pediatr Res $2005 ; 57: 419-423$.

26 Bottcher T, Ren H, Goiny M, et al. Clindamycin is neuroprotective in experi-

- mental Streptococcus pneumoniae meningitis compared with ceftriaxone. Neurochem 2004; 91:1450-1460.

How antibiotic therapy contributes to the release of bacterial components and subsequent neurological damage.

27 Cottagnoud P, Pfister M, Acosta F, et al. Daptomycin is highly efficacious

- against penicillin-resistant and penicillin- and quinolone-resistant pneumococci in experimental meningitis. Antimicrob Agents Chemother 2004; 48: 3928-3933.

This is the first report on the use of a cyclic lipopeptide for the treatment of pneumococcal meningitis.

28 Echchannaoui H, Bachmann P, Letiembre M, et al. Regulation of Streptococ- cus pneumoniae distribution by Toll-like receptor 2 in vivo. Immunobiology 2005; 210:229-236

Molecular mechanisms of innate immunity and recognition of pathogens.

29 Echchannaoui $\mathrm{H}$, Frei $\mathrm{K}$, Letiembre $\mathrm{M}$, et al. CD14 deficiency leads to - increased MIP-2 production, CXCR2 expression, neutrophil transmigration, and early death in pneumococcal infection. J Leukoc Biol 2005; 78:705715 .

Molecular mechanisms of innate immunity and recognition of pathogens

30 Letiembre M, Echchannaoui H, Ferracin F, et al. Toll-like receptor-2 deficiency is associated with enhanced brain TNF gene expression during pneumococcal meningitis. J Neuroimmunol 2005; 168:21-33.

31 Brandt CT, Lundgren JD, Frimodt-Moller N, et al. Blocking of leukocyte accu-

- mulation in the cerebrospinal fluid augments bacteremia and increases lethality in experimental pneumococcal meningitis. J Neuroimmunol 2005; 166: 126-131.

The dichotomous effect of blocking leukocytes on central nervous system complication and systemic disease.

32 Angstwurm K, Hanisch UK, Gassemi T, et al. Tyrosine kinase inhibition - reduces inflammation in the acute stage of experimental pneumococcal meningitis. Infect Immun 2004; 72:3294-3298.

Effect of modulation of leukocyte recruitment on CSF inflammation in a model of pneumococcal cell wall-induced meningitis.

33 Brandt CT, Lundgren JD, Lund SP, et al. Attenuation of the bacterial load in

- blood by pretreatment with granulocyte-colony-stimulating factor protects rats from fatal outcome and brain damage during Streptococcus pneumoniae meningitis. Infect Immun 2004; 72:4647-4653.

How modulation of inflammation affects systemic disease and brain damage in pneumoccal meningitis.

34 Koedel U, Rupprecht T, Angele B, et al. MyD88 is required for mounting a - robust host immune response to Streptococcus pneumoniae in the CNS. Brain 2004; 127:1437-1445.

The role of MyD88 as a common downstream effector of pathogen recognition in pneumococcal meningitis.

35 Paul R, Angele B, Sporer B, et al. Inflammatory response during bacterial meningitis is unchanged in Fas- and Fas ligand-deficient mice. J Neuroimmunol 2004; 152:78-82.

36 Chaudhuri A. Adjunctive dexamethasone treatment in acute bacterial menin-• gitis. Lancet Neurol 2004; 3:54-62.

Review on the use of dexamethasone in the adjuvant therapy of bacterial meningitis.

37 Irazuzta J, Pretzlaff RK, DeCourten-Myers G, et al. Dexamethasone decreases neurological sequelae and caspase activity. Intensive Care Med $2005 ; 31: 146-150$. 
38 Van de Beek D, de Gans J. Dexamethasone and pneumococcal meningitis. - Ann Intern Med 2004; 141:327.

The beneficial effect of dexamethasone on mortality was attributable to improvement in systemic complications, but not neurological sequelae.

39 Mclntyre PB, Macintyre CR, Gilmour R, Wang H. A population based study

- of the impact of corticosteroid therapy and delayed diagnosis on the outcome of childhood pneumococcal meningitis. Arch Dis Child 2005; 90: 391-396.

Early recognition of disease and dexamethasone therapy might improve the neurological outcome.

40 Casella EB, Cypel S, Osmo AA, et al. Sequelae from meningococcal menin-

- gitis in children: a critical analysis of dexamethasone therapy. Arq Neuropsiquiatr $2004 ; 62: 421-428$.

The effect of dexamethasone treatment depends on the etiological agents.

41 Gerber J, Bottcher T, Hahn M, et al. Increased mortality and spatial memory deficits in TNF-alpha-deficient mice in ceftriaxone-treated experimental pneumococcal meningitis. Neurobiol Dis 2004; 16:133-138.

42 Meli DN, Loeffler JM, Baumann $\mathrm{P}$, et al. In pneumococcal meningitis a novel

- water-soluble inhibitor of matrix metalloproteinases and TNF-alpha converting enzyme attenuates seizures and injury of the cerebral cortex. J Neuroimmunol 2004; 151:6-11.

The effect of an MMP inhibitor in experimental pneumococcal meningitis.

43 Gerber J, Lotz M, Ebert S, et al. Melatonin is neuroprotective in experimental - Streptococcus pneumoniae meningitis. J Infect Dis 2005; 191:783-790.

One of the few experimental therapeutic approaches that prevent hippocampal damage during pneumococcal meningitis.

44 Aminpour S, Tinling SP, Brodie HA. Role of tumor necrosis factor-alpha in sensorineural hearing loss after bacterial meningitis. Otol Neurotol 2005; 26:602-609.

45 Kastenbauer S, Angele B, Sporer B, et al. Patterns of protein expression in

- infectious meningitis: a cerebrospinal fluid protein array analysis. J Neuroimmunol 2005; 164:134-139.

Using a new technique, namely protein arrays, the authors were able to produce

a large expression pattern of cytokines and chemokines.

46 Paul R, Koedel U, Pfister HW. Development of adjunctive therapies for bac-

-. terial meningitis and lessons from knockout mice. Neurocrit Care 2005; 2 313-324.

A comprehensive review on the use of knockout mice models for the research on bacterial meningitis, and their advantages and limitations.

47 Mitchell L, Smith SH, Braun JS, et al. Dual phases of apoptosis in pneumococcal meningitis. J Infect Dis 2004; 190:2039-2046.

48 Bifrare YD, Kummer J, Joss $\mathrm{P}$, et al. Brain-derived neurotrophic factor pro-

- tects against multiple forms of brain injury in bacterial meningitis. J Infect Dis $2005 ; 191: 40-45$.

The effect of BDNF therapy on neurological sequelae.

49 Li L, Shui QX, Li X. Neuroprotective effects of brain-derived neurotrophic

- factor (BDNF) on hearing in experimental pneumococcal meningitis. J Child Neurol 2005; 20:51-56.

The effect of BDNF therapy on neurological sequelae.
50 Zweigner J, Jackowski S, Smith SH, et al. Bacterial inhibition of phosphati- dylcholine synthesis triggers apoptosis in the brain. J Exp Med 2004; 200: 99-106.

Possibly a new mechanism involved in the triggering of apoptotic cell death during bacterial meningitis.

51 Gerber J, Pohl K, Sander V, et al. Rifampin followed by ceftriaxone for experimental meningitis decreases lipoteichoic acid concentrations in cerebrospinal fluid and reduces neuronal damage in comparison to ceftriaxone alone. Antimicrob Agents Chemother 2003; 47:1313-1317.

52 Echchannaoui $\mathrm{H}$, Frei $\mathrm{K}$, Schnell $\mathrm{C}$, et al. Toll-like receptor 2-deficient mice are highly susceptible to Streptococcus pneumoniae meningitis because of reduced bacterial clearing and enhanced inflammation. J Infect Dis 2002; 186:798-806.

53 Miwa K, Asano M, Horai R, et al. Caspase 1-independent IL-1beta release and inflammation induced by the apoptosis inducer Fas ligand. Nat Med $1998 ; 4: 1287-1292$

54 Liles WC, Kiener PA, Ledbetter JA, et al. Differential expression of Fas (CD95) and Fas ligand on normal human phagocytes: implications for the regulation of apoptosis in neutrophils. J Exp Med 1996; 184:429-440.

55 Molyneux E. Dexamethasone in the treatment of pediatric bacterial meningi-

-. tis in developing countries: is it beneficial? Adv Exp Med Biol 2005; 568: 175-188.

The effect of dexamethasone on outcome in bacterial meningitis in different regions of the world.

56 Mclntyre P. Should dexamethasone be part of routine therapy of bacterial

- meningitis in industrialised countries? Adv Exp Med Biol 2005; 568:189197.

The effect of dexamethasone on outcome in bacterial meningitis in different regions of the world.

57 Leib SL, Heimgartner C, Bifrare YD, et al. Dexamethasone aggravates hippocampal apoptosis and learning deficiency in pneumococcal meningitis in infant rats. Pediatr Res 2003; 4:4.

58 Leib SL, Clements JM, Lindberg RL, et al. Inhibition of matrix metalloproteinases and tumour necrosis factor alpha converting enzyme as adjuvant therapy in pneumococcal meningitis. Brain 2001; 124:1734-1742.

59 Leib SL, Leppert D, Clements J, Täuber MG. Matrix metalloproteinases contribute to brain damage in experimental pneumococcal meningitis. Infect Immun 2000; 68:615-620.

60 Schaper M, Gergely S, Lykkesfeldt J, et al. Cerebral vasculature is the major target of oxidative protein alterations in bacterial meningitis. J Neuropathol Exp Neurol 2002; 61:605-613.

61 Braun JS, Novak R, Herzog KH, et al. Neuroprotection by a caspase inhibito in acute bacterial meningitis. Nat Med 1999; 5:298-302.

62 Gianinazzi C, Grandgirard D, Imboden $\mathrm{H}$, et al. Caspase-3 mediates hippocampal apoptosis in pneumococcal meningitis. Acta Neuropathol (Berl) 2003; 105:499-507.

63 Li L, Shui QX, Zhao ZY. Regulation of brain-derived neurotrophic factor (BDNF) expression following antibiotic treatment of experimental bacterial meningitis. J Child Neurol 2003; 18:828-834.

64 Nau R, Bruck W. Neuronal injury in bacterial meningitis: mechanisms and implications for therapy. Trends Neurosci 2002; 25:38-45. 